\title{
High Sugar Intake and Development of Skeletal Muscle Insulin Resistance and Inflammation in Mice: A Protective Role for PPAR- $\delta$ Agonism
}

\author{
Elisa Benetti, ${ }^{1}$ Raffaella Mastrocola, ${ }^{2}$ Mara Rogazzo, ${ }^{1}$ Fausto Chiazza, ${ }^{1}$ Manuela Aragno, \\ Roberto Fantozzi, ${ }^{1}$ Massimo Collino, ${ }^{1}$ and Marco A. Minetto ${ }^{3}$ \\ ${ }^{1}$ Department of Drug Science and Technology, University of Turin, Via Giuria 9, 10125 Torino, Italy \\ ${ }^{2}$ Department of Clinical and Biological Sciences, University of Turin, Corso Raffaello 30, 10125 Torino, Italy \\ ${ }^{3}$ Division of Endocrinology, Diabetology and Metabolism, Department of Medical Sciences, University of Turin, \\ Corso Dogliotti 14, 10126 Torino, Italy
}

Correspondence should be addressed to Marco A. Minetto; marco.minetto@unito.it

Received 24 March 2013; Revised 15 May 2013; Accepted 16 May 2013

Academic Editor: Daniel Konrad

Copyright (c) 2013 Elisa Benetti et al. This is an open access article distributed under the Creative Commons Attribution License, which permits unrestricted use, distribution, and reproduction in any medium, provided the original work is properly cited.

\begin{abstract}
Peroxisome Proliferator Activated Receptor (PPAR) $\delta$ agonists may serve for treating metabolic diseases. However, the effects of PPAR- $\delta$ agonism within the skeletal muscle, which plays a key role in whole-body glucose metabolism, remain unclear. This study aimed to investigate the signaling pathways activated in the gastrocnemius muscle by chronic administration of the selective PPAR$\delta$ agonist, GW0742 (1 mg/kg/day for 16 weeks), in male C57Bl6/J mice treated for 30 weeks with high-fructose corn syrup (HFCS), the major sweetener in foods and soft-drinks (15\% wt/vol in drinking water). Mice fed with the HFCS diet exhibited hyperlipidemia, hyperinsulinemia, hyperleptinemia, and hypoadiponectinemia. In the gastrocnemius muscle, HFCS impaired insulin and AMPactivated protein kinase signaling pathways and reduced GLUT-4 and GLUT-5 expression and membrane translocation. GW0742 administration induced PPAR- $\delta$ upregulation and improvement in glucose and lipid metabolism. Diet-induced activation of nuclear factor- $\kappa \mathrm{B}$ and expression of inducible-nitric-oxide-synthase and intercellular-adhesion-molecule-1 were attenuated by drug treatment. These effects were accompanied by reduction in the serum concentration of interleukin- 6 and increase in muscular expression of fibroblast growth factor-21. Overall, here we show that PPAR- $\delta$ activation protects the skeletal muscle against the metabolic abnormalities caused by chronic HFCS exposure by affecting multiple levels of the insulin and inflammatory cascades.
\end{abstract}

\section{Introduction}

In healthy humans, skeletal muscle accounts for $\sim 70-80 \%$ of the insulin-stimulated glucose uptake, being the major site of glucose disposal and, thus, exerting a key role in regulating whole body glucose homeostasis. Accordingly, understanding changes that occur to this tissue during obesity and diabetes development is crucial to elucidate the underlying causes of insulin resistance and to reveal new targets for its treatment. Insulin resistance in skeletal muscle has long been recognized as a characteristic feature of type 2 diabetes and plays a major role in the pathogenesis of the disease [1]. Although several epidemiological data have shown that the consumption of added sugars as ingredients in processed or prepared foods and caloric beverages has dramatically increased over the last decades, most of the experimental studies investigating the development of insulin resistance in the skeletal muscle have been based on genetic manipulation or use of high fat diets [2-4]. In contrast, the molecular mechanisms underlying the detrimental effects of sugar, mainly those on skeletal muscle, are not completely understood. In the present study, we used a previously developed mouse model of chronic exposure to high-fructose corn syrup (HFCS) [5] to investigate the deleterious effects of high sugar intake on skeletal muscle. HFCS syrup, used as an ingredient in processed or prepared foods and caloric 
beverages, is synthesized by refining corn starch, contains $55 \%$ fructose and $42 \%$ glucose and to date accounts for over $40 \%$ of all added caloric sweeteners [6].

The Peroxisome Proliferator Activated Receptor (PPAR) superfamily of transcription factors, that includes the isoforms PPAR- $\alpha$, PPAR- $\delta$, and PPAR- $\gamma$, has been widely shown to exert crucial roles in energy homeostasis regulation and glucose metabolism. PPAR isoforms display tissue-specific expression and gene-regulatory profiles. PPAR- $\delta$, one of the most promising pharmacological target implicated in obesity-associated insulin resistance [7], is highly expressed in skeletal muscle, at 10- and 50-folds higher levels compared with PPAR- $\alpha$ and PPAR- $\gamma$, respectively [8]. However, its potential effects in affecting skeletal muscle glucose intake and insulin sensitivity are only now being elucidated. Schuler et al. [9] showed that mice in which PPAR- $\delta$ is selectively ablated in skeletal myocytes exhibit fiber-type switching, obesity, and type 2 diabetes. Besides, a very recent paper has suggested that the improvement of glucose homeostasis by angiotensin receptor blockers in hypertensive patients involves a selective PPAR- $\delta$ activation in the skeletal muscle [10]. So far, the exact molecular mechanisms underlying the observed PPAR- $\delta$-induced changes have not yet been determined. Hence, the present study aimed to determine whether chronic administration of the selective PPAR- $\delta$ agonist GW0742 in HFCS-fed mice may ameliorate the impairment of signaling pathways triggered in skeletal muscles by chronic high sugar intake. Several studies have revealed that a large number of muscle-derived secretory cytokines (collectively termed myokines) can act locally in an autocrine/paracrine manner, linking skeletal muscle to regulation of physiological processes in other tissues. We have, thus, also investigated whether PPAR- $\delta$ agonism may affect the serum levels of the well-known myokine interleukin-6 (IL-6) and the muscular expression of a member of the fibroblast growth factor (FGF) superfamily, FGF-21, a recently identified myokine involved in the interorgan communication [11]. To further extend our investigation on the ability of PPAR- $\delta$ agonism to modulate inflammatory pathways involved in local insulin resistance pathogenesis, the effects of PPAR- $\delta$ activation on nuclear translocation of the transcription nuclear factor-kappaB (NF$\kappa \mathrm{B})$ and expression of its target genes have also been studied.

\section{Materials and Methods}

2.1. Animals and Diets. Four-week-old male C57Bl6/J mice (Harlan-Italy; Udine, Italy) were housed in a controlled environment at $25 \pm 2^{\circ} \mathrm{C}$ with alternating 12-h light and dark cycles. They were provided with a Piccioni pellet diet (n. 48, Gessate Milanese, Italy) and water ad libitum. All the animals were fed with a normal pellet diet for 1 week prior to the experiment. The animals were then allocated to two dietary regimens, chow diet and normal drinking water (control) or a chow diet and 15\% (wt/vol) HFCS solution in drinking water (HFCS) for 30 weeks. All diets contained a standard mineral and vitamin mixture. The concentration of HFCS solution as well as the period of dietary manipulation was chosen according to previous animal studies investigating the metabolic effects of long-term (6-7 months) access to HFCS. Body mass, intake of water, and food were recorded weekly. Animal care was in compliance with Italian regulations on the protection of animals used for experimental and other scientific purposes (DM 116/92), and the experiment was approved by the Turin University Ethics Committee.

2.2. Drug Administration. After the initial period of 14 weeks of dietary manipulation, each of the two diet groups (control and HFCS diet) was further subdivided to obtain four different treatment groups: chow diet and normal drinking water (control, $n=10$ ), chow diet supplemented with GW0742 (1 mg/kg/day) and normal drinking water (control+ GW, $n=6$ ), chow diet and 15\% (wt/vol) HFCS solution in drinking water (HFCS, $n=10$ ), and chow diet supplemented with GW0742 (1 mg/kg/day) and 15\% (wt/vol) HFCS solution in drinking water (HFCS + GW, $n=10)$. The drug was daily administered with the food for the last 16 weeks, and the mice were allowed to continue to feed on their respective diets until the end of the study. GW0742 is a highly potent and selective PPAR- $\delta$ agonist (murine $\mathrm{EC}_{50}: 28 \mathrm{nM}$ for PPAR$\delta ; 8,900 \mathrm{nM}$ for PPAR- $\alpha$; $>10,000 \mathrm{nM}$ for PPAR- $\gamma$ ), with an acceptable pharmacokinetic profile and activity in vivo [12]. The dose and the kinetics of administration were chosen based on those we have previously shown to improve glucose tolerance and insulin sensitivity in vivo [5].

2.3. Oral Glucose Tolerance Test (OGTT). One day before the mice were due to be killed, the OGTT was performed after a fasting period of $6 \mathrm{~h}$ by administering glucose $(2 \mathrm{~g} / \mathrm{kg})$ by oral gavage. Once before administration and 15, 30, 60, 90, 120 , and $150 \mathrm{~min}$ afterward, blood was obtained from the saphenous vein, and glucose concentration was measured with a conventional Glucometer (Accu-Check Compact kit, Roche Diagnostics Gmbh, Mannheim, Germany).

2.4. Blood Biochemical Analysis. After 16 weeks from the start of the drug treatment (i.e., after 30 weeks of dietary manipulation), the mice were anaesthetised with i.p. injection $(30 \mathrm{mg} / \mathrm{kg}$ ) of Zoletil 100 (Laboratories Virbac, France) and killed by aortic exsanguination. Blood samples were collected, and plasma was isolated. Glycemia was measured using the Accu-Check Compact kit. The serum lipid profile was determined by measuring the content of triglycerides, total cholesterol, high-density lipoprotein (HDL), and low density lipoprotein (LDL) by standard enzymatic procedures using reagent kits (Hospitex Diagnostics, Florence, Italy). Plasma leptin and adiponectin levels were measured using enzyme-linked immunosorbent assay (ELISA) kits (Leptin and Adiponectin Mouse ELISA Kits, Abcam, Cambridge UK). The gastrocnemius muscle and epididymal fat were isolated, weighed, rapidly freeze-clamped with liquid nitrogen, and stored at $-80^{\circ} \mathrm{C}$.

2.5. Tissue Extracts. Gastrocnemius extracts were prepared using the Meldrum method [13] with modification. Briefly, gastrocnemius were homogenised at $10 \%(\mathrm{w} / \mathrm{v})$ in a PotterElvehjem homogenizer (Wheaton, NJ, USA) using a 
homogenisation buffer containing $20 \mathrm{mM}$ HEPES, $\mathrm{pH}$ 7.9, $1 \mathrm{mM} \mathrm{MgCl}_{2}, 0.5 \mathrm{mM}$ EDTA, $1 \mathrm{mM}$ EGTA, $1 \mathrm{mM}$ dithiothreitol (DTT), $0.5 \mathrm{mM}$ phenylmethylsulfonyl fluoride (PMSF), $5 \mu \mathrm{g} / \mathrm{mL}$ aprotinin, and $2.5 \mu \mathrm{g} / \mathrm{mL}$ leupeptin. Homogenates were centrifuged at $4000 \mathrm{RPM}$ at $4^{\circ} \mathrm{C}$ for $5 \mathrm{~min}$. Supernatants were removed and centrifuged at $14000 \mathrm{RPM}$ at $4^{\circ} \mathrm{C}$ for 40 minutes to obtain the cytosolic fraction. The pelleted nuclei were resuspended in an extraction buffer and centrifuged at $14000 \mathrm{RPM}$ for 20 minutes at $4^{\circ} \mathrm{C}$. The supernatants thus obtained, containing nuclear proteins, were carefully removed. The amount of proteins contained in the cytosolic and nuclear fraction was determined using a BCA protein assay following the manufacturers' instructions. Samples were stored at $-80^{\circ} \mathrm{C}$ until use.

2.6. Skeletal Muscle Triglyceride Level. Skeletal muscle triglycerides were extracted from gastrocnemius homogenates and assayed using reagent kits according to the manufacturer's instructions (Triglyceride Quantification Kit, Abnova Corporation, Aachen, Germany).

2.7. Western Blot Analysis. About $60 \mu \mathrm{g}$ of total proteins was loaded for western blot experiments. Proteins were separated by $8 \%$ sodium dodecyl sulphate-polyacrylamide gel electrophoresis (SDS-PAGE) and transferred to a polyvinyldene difluoride (PVDF) membrane, which was then incubated with a primary antibody (rabbit anti-PPAR- $\delta$, dilution $1: 500$; rabbit antitotal GSK-3 $\beta$, dilution 1:200; goat anti-pGSK-3 $\beta$ Ser $^{9}$, dilution 1:200; rabbit antitotal Akt, dilution 1:1000; mouse anti-pAkt Ser ${ }^{473}$, dilution 1:1000; goat anti-ICAM1, dilution 1:500; rabbit antitotal IRS-1, dilution 1:200; goat anti-pIRS-1 Ser ${ }^{307}$, dilution 1:200; rabbit anti-GLUT-4, dilution 1: 2000; rabbit anti-GLUT-5, dilution 1:100; rabbit antiiNOS, dilution $1: 200$; rabbit anti-NF- $\kappa$ B dilution $1: 1000$; rabbit antitotal AMPK, dilution 1:1000; rabbit anti-pAMPK $\mathrm{Thr}^{172}$, dilution 1:1000; rabbit antitotal ACC, dilution 1:500; rabbit anti-pACC Ser ${ }^{79}$, dilution 1:1000; rabbit anti-CPT-1, dilution $1: 200$ ). Blots were then incubated with a secondary antibody conjugated with horseradish peroxidase (dilution $1: 10000$ ) and developed using the ECL detection system. The immunoreactive bands were visualised by autoradiography and the density of the bands was evaluated densitometrically using Gel-Pro Analyzer 4.5, 2000 software (Media Cybernetics, Silver Spring, MD, USA). The membranes were stripped and incubated with tubulin monoclonal antibody (dilution $1: 5000$ ) and subsequently with an anti-mouse antibody (dilution $1: 10000)$ to assess gel-loading homogeneity.

2.8. Immunohistochemistry. Immunohistochemical staining was performed on $10-\mu \mathrm{m}$ acetone fixed cryostatic sections of gastrocnemius. Nonspecific binding sites were blocked for $1 \mathrm{~h}$ with 3\% BSA in PBS. For immunodetection of glucose transporter type-4 (GLUT-4), sections were incubated overnight with rabbit anti-GLUT-4 antibody (Abcam), dilution 1:200, and for 1 hour with goat anti-rabbit IgG-HRP conjugated secondary antibody (Bio-Rad Laboratories, Hercules, CA, USA). For detection of glucose transporter type 5 (GLUT-5), sections were incubated overnight with rabbit anti-GLUT-5 antibody (Abcam), dilution 1:50, for 1 hour with swine antirabbit IgG-biotinylated secondary antibody (Dako, Glostrup, Denmark), and for 1 hour with Streptavidin HRP conjugate (Southern Biotech, Birmingham, AL, USA). The specific staining was detected with diaminobenzidine (DAB, SigmaAldrich), and sections were visualized with Olympus-Bx4I microscope connected by a photographic attachment (Carl Zeiss, Oberkochen, Germany). For each antibody, a negative control was included in which the primary antibody was replaced with a nonimmune isotypic control antibody.

2.9. Determination of IL-6 and FGF-21. Serum levels of IL6 and FGF-21 levels in gastrocnemius homogenates were measured by ELISA according to the manufacturer's instructions (Mouse FGF-21 and IL-6 ELISA kits, R\&D Systems, Abingdon, UK).

2.10. Materials. Unless otherwise stated, all compounds were purchased from the Sigma-Aldrich Company Ltd. (St. Louis, MO, USA). The BCA Protein Assay kit and SuperBlock blocking buffer were from Pierce Biotechnology Inc. (Rockford, IL, USA), and PVDF was from the Millipore Corporation (Bedford, Massachusetts, USA). Antibodies were from Cell-Signaling Technology (Beverly, MA, USA), Santa Cruz Biotechnology (Santa Cruz, CA, USA), and Abcam (Cambridge, $\mathrm{CB}, \mathrm{UK})$. The anti-mouse, anti-rabbit, and anti-goat horseradish peroxidase-linked antibodies were from Santa Cruz Biotechnology (Santa Cruz, CA, USA), and Luminol ECL was from PerkinElmer (Waltham Massachusetts, USA).

2.11. Statistical Analysis. All values in both the text and figures are expressed as mean \pm SD for $n$ observations. One-way analysis of variance with Dunnett's post-hoc test was performed using the GraphPad Prism version 4.02 for Windows (GraphPad Software, San Diego, California, USA), and $P$ values below 0.05 were considered as significant.

\section{Results}

3.1. Effects of HFCS Diet and GW0742 Administration on Body Mass Change, Food Intake, and Blood Parameters. After 30 weeks of dietary manipulation, mice on HFCS group had significantly higher body mass than the control group, with an increase in body mass over 30\% (36.00 $\pm 1.41 \mathrm{~g}$ versus $32.25 \pm 1.67 \mathrm{~g} ; P<0.01)$, whereas GW0742 administration induced a slight but not significant reduction in body mass $(35.00 \pm 2.83 \mathrm{~g})$. Epididymal fat mass was increased by HFCS manipulation in comparison to control diet $(4.22 \pm 0.35 \%$ body mass versus $3.66 \pm 0.29 \%$ body mass; $P<0.01$ ), and values were reduced to the control level by drug administration $(3.86 \pm 0.33 \%$ body mass). In contrast, neither dietary manipulation nor drug treatment affected gastrocnemius mass (\% body mass: $0.97 \pm 0.19$ control, $0.92 \pm 0.09$ HFCS, and $0.92 \pm 0.06 \mathrm{HFCS}+\mathrm{GW})$. As we previously reported [5], the HFCS diet caused a significant increase in serum triglycerides, total cholesterol, and LDL concentrations and a marked decrease in the HDL levels. GW0742 administration 
reverted the deleterious effects of HFCS diet on the serum lipid profile. Interestingly, the HFCS diet significantly affected insulin sensitivity. A significant increase in serum insulin levels was observed in mice of HFCS group compared to control mice $(2.26 \pm 0.51 \mu \mathrm{g} / \mathrm{L}$ versus $1.27 \pm 0.07 \mu \mathrm{g} / \mathrm{L})$, and this increase was almost completely abolished by GW0742 (1.51 \pm $0.46 \mu \mathrm{g} / \mathrm{L})$. Fasting glucose concentrations were elevated in serum of HFCS animals in comparison to control animals $(103.4 \pm 12.0 \mathrm{mg} / \mathrm{dL}$ versus $78.7 \pm 0.3 \mathrm{mg} / \mathrm{dL})$ and reduced to control levels by GW0742 $(81.3 \pm 10.9 \mathrm{mg} / \mathrm{dL})$. Moreover, HFCS mice showed a significant impairment in glucose tolerance to exogenously administered glucose. Although all the groups reached a glycemic peak at $15 \mathrm{~min}$ postglucose challenge (control: $223.1 \pm 12.0 \mathrm{mg} / \mathrm{dL}$; HFCS: $212.7 \pm$ $7.3 \mathrm{mg} / \mathrm{dL} ; \mathrm{HFCS}+\mathrm{GW}: 198.8 \pm 10.3 \mathrm{mg} / \mathrm{dL}$ ), glycemic levels at 30-60 min post glucose challenge in HFCS-fed mice were higher than those recorded in the control group $(30 \mathrm{~min}$ : $182.9 \pm 8.3 \mathrm{mg} / \mathrm{dL}$ versus $129.4 \pm 8.0 \mathrm{mg} / \mathrm{dL}, P<0.05 ; 60 \mathrm{~min}$ : $130.7 \pm 10.3 \mathrm{mg} / \mathrm{dL}$ versus $96.8 \pm 4.0 \mathrm{mg} / \mathrm{dL}, P<0.05)$. GW0742 significantly $(P<0.05)$ improved glucose tolerance in HFCS-fed mice, showing significantly reduced glucose concentrations at both 30 and $60 \mathrm{~min}$ postglucose challenge $(89.7 \pm 5.2 \mathrm{mg} / \mathrm{dL}$ and $86.7 \pm 4.3 \mathrm{mg} / \mathrm{dL}$, resp.).

Data on the effects of dietary manipulation and chronic GW0742 treatment on serum levels of IL-6, adiponectin, and leptin are reported in Table 1 . The experimental diet caused a more than fourfold increase in serum IL- 6 concentrations, whereas GW0742 administration significantly decreased the IL-6 levels. Adiponectin and leptin showed different patterns: in fact, the level of adiponectin in HFCS mice was lower than in control mice, while that of leptin increased versus controls. When GW0742 was administered to HFCS mice there was a significant increase $(P<0.01)$ in the adiponectin levels associated with a significant decrease $(P<0.01)$ in leptin serum concentration.

It must be noted that in control mice GW0742 had no significant effect on any of the previously described metabolic parameters.

\subsection{Effect of GW0742 on Skeletal Muscle PPAR- $\delta$ Expression.} As shown in Figure 1, HFCS diet did not affect PPAR$\delta$ protein level expression in the mouse gastrocnemius. In contrast, daily administration of GW0742 resulted in a twofold increase in expression of its pharmacological target, with maximum effect in the presence of dietary manipulation.

\subsection{The Effects of HFCS Diet on Insulin Signal Transduction} Were Reverted by GW0742 Administration. The HFCS diet did not alter the protein expression of IRS-1, Akt, or GSK$3 \beta$ compared to the control group. However, HFCS caused a marked increase in Ser $^{307}$ phosphorylation of IRS-1 in parallel with reduced Ser ${ }^{473}$ phosphorylation of Akt (Figures 2(a) and 2(b)). Ser ${ }^{9}$ phosphorylation of GSK-3 $\beta$, a downstream target of Akt, was also reduced in the presence of HFCS (Figure 2(c)), suggestive of impaired insulin signaling downstream of IRS-1. Most notably, GW0742 significantly attenuated all the effects of HFCS on IRS-1, Akt, and GSK-3 $\beta$ phosphorylation, measured at the steady state.
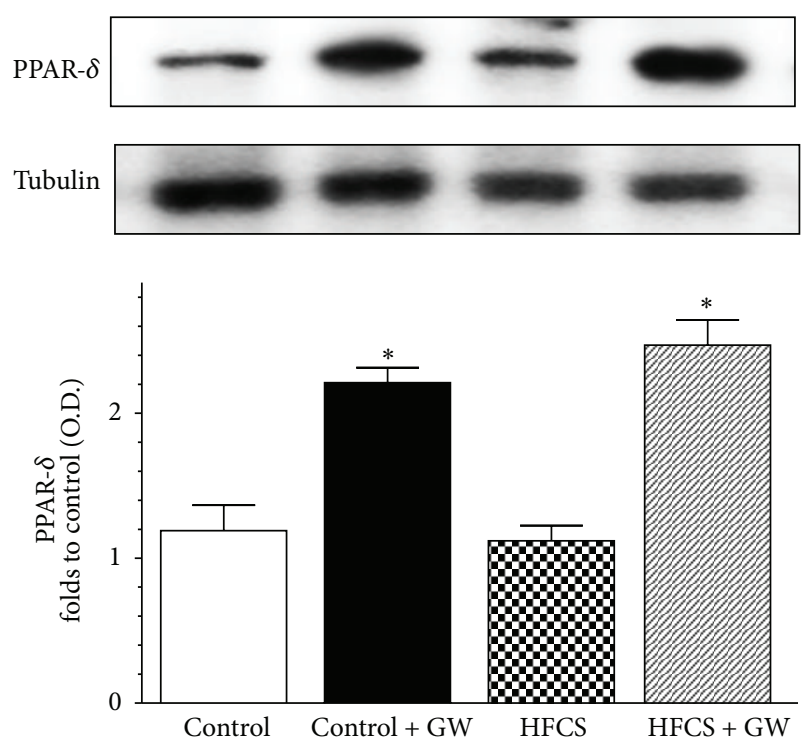

FIGURE 1: Effects of dietary manipulation and GW0742 treatment on PPAR- $\delta$ expression in the mouse gastrocnemius. Protein expression was measured by western blot analysis in gastrocnemius homogenates of mice fed with a standard (control) or HFCS diet (HFCS) in the absence or presence of GW0742 treatment $(1 \mathrm{mg} / \mathrm{kg} /$ day) (control + GW; HFCS + GW). Densitometric analysis of the bands is expressed as relative optical density (O.D.), corrected for the corresponding tubulin, and normalized using the related control band. Data are means \pm SD of three separate experiments. ${ }^{*} P<0.01$ versus HFCS.

3.4. Effects of HFCS Diet and GW0742 Treatment on GLUT4 and GLUT-5 Expression and Translocation. In comparison to control animals, GLUT-4 expression was reduced in the gastrocnemius of HFCS mice, without reaching a statistical significance, and increased following drug treatment (Figure 3(a)). Similarly, the HFCS diet markedly reduced GLUT-5 expression, whereas GW0742 administration resulted in a significant increase in GLUT-5 expression (Figure 3(c)). Notably, GW0742 treatment not only increased carriers expression levels but also induced a significant membrane translocation, thus increasing muscle glucose uptake (Figures 3(b) and 3(d)).

\subsection{Effects of HFCS Diet and GW0742 Treatment on Skeletal} Muscle Triglyceride Content and AMPK/ACC and CPT-1 Signaling Pathway. The triglyceride content was doubled in the gastrocnemius of HFCS mice in comparison with control animals, whereas skeletal muscle triglyceride accumulation was significantly reduced by GW0742 administration (Figure 4).

Changes in the phosphorylation/activation of the AMPactivated protein kinase (AMPK)/acetyl-CoA carboxylase (ACC) system, whose central role in the regulation of cellular lipid homeostasis is well known, were evaluated by immunoblotting experiments on gastrocnemius homogenates. As reported in Figure 5, there was no significant effect of HFCS feeding or drug treatment on total AMPK and ACC protein content. In contrast, chronic HFCS exposure markedly reduced $\mathrm{Thr}^{172}$ phosphorylation of AMPK and 
TABLE 1: Effects of chronic in vivo treatment with GW0742 on mouse blood parameters after 30 weeks of dietary manipulation.

\begin{tabular}{|c|c|c|c|c|}
\hline & Control $(n=10)$ & Control + GW0742 $(n=6)$ & $\operatorname{HFCS}(n=10)$ & HFCS + GW0742 $(n=10)$ \\
\hline IL-6 (pg/mL) & $20.80 \pm 2.11$ & $18.90 \pm 4.22$ & $91.55 \pm 16.47^{*}$ & $28.80 \pm 7.99^{\S}$ \\
\hline Adiponectin $(\mu \mathrm{g} / \mathrm{mL})$ & $4.53 \pm 0.23$ & $4.75 \pm 0.46$ & $1.93 \pm 0.08^{*}$ & $3.69 \pm 0.43^{* \S}$ \\
\hline Leptin (pg/mL) & $206.65 \pm 18.77$ & $198.07 \pm 22.17$ & $446.67 \pm 52.61^{*}$ & $266.12 \pm 41.21^{* \S}$ \\
\hline
\end{tabular}

HFCS: high-fructose corn syrup; IL-6: interleukin-6.

Data are means \pm S.D.

${ }^{*} P<0.01$ versus Control.

${ }^{\S} P<0.01$ versus HFCS.

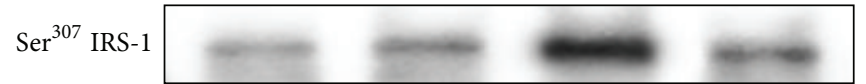

Total IRS-1
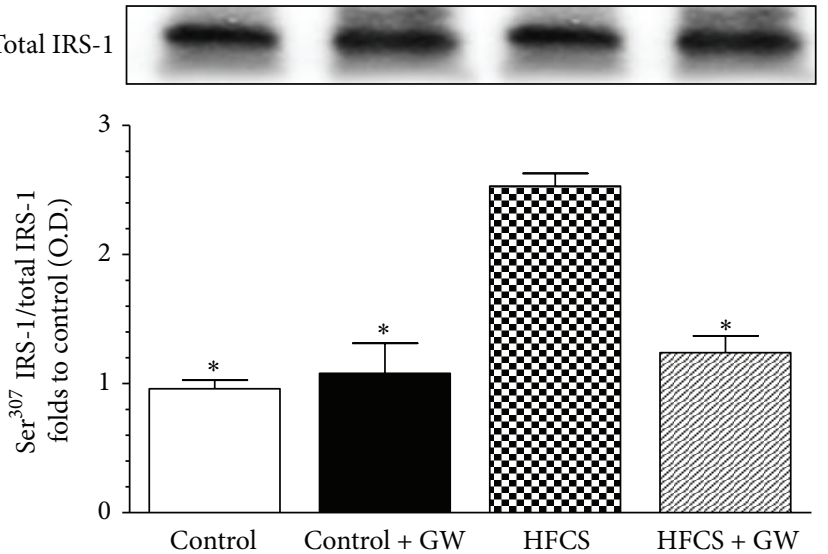

(a)
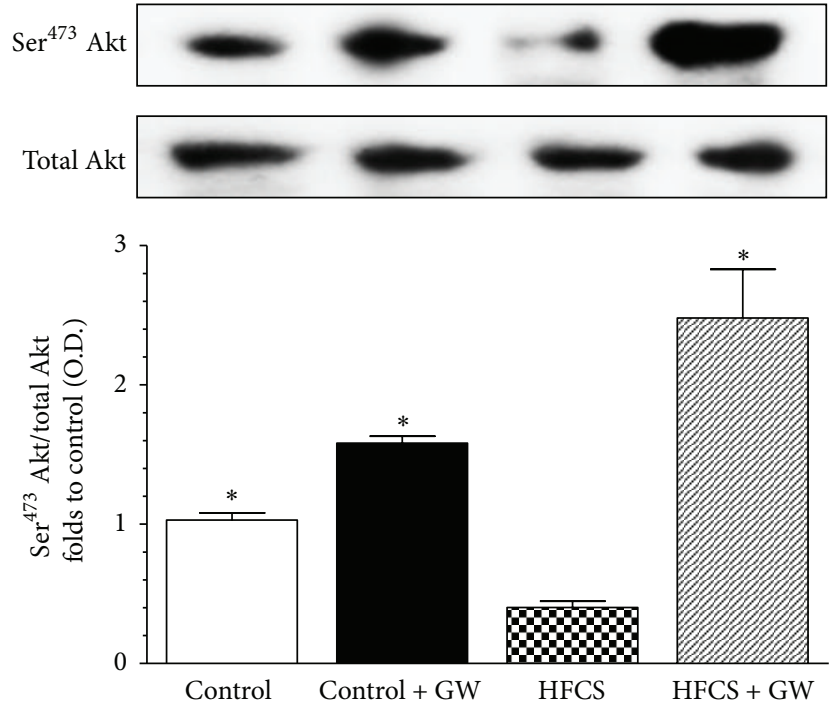

(b)
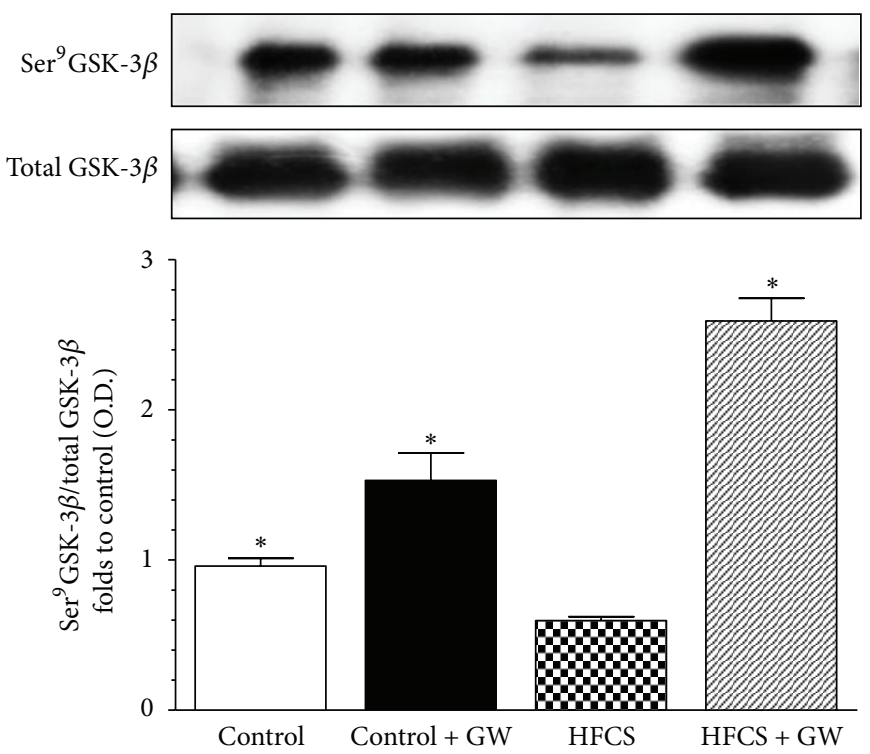

(c)

FIGURE 2: Effects of GW0742 treatment on insulin signal transduction in the gastrocnemius of mice fed with HFCS diet. Total IRS-1 protein expression and $\mathrm{Ser}^{307}$ phosphorylation (a), total Akt protein expression and $\mathrm{Ser}^{473}$ phosphorylation (b), and total GSK-3 $\beta$ protein expression and $\operatorname{Ser}^{9}$ phosphorylation (c) were analyzed by western blot on the gastrocnemius homogenates obtained from mice fed with a standard (control) or HFCS diet (HFCS) for 30 weeks and treated with GW0742 (1 mg/kg/day) added during the last 16 weeks (control + GW; HFCS + GW). Densitometric analysis of the bands is expressed as relative optical density (O.D.), corrected for the corresponding tubulin contents, and normalized using the related control band. The data are means \pm SD of three separate experiments. ${ }^{*} P<0.01$ versus HFCS. 


\section{GLUT-4}

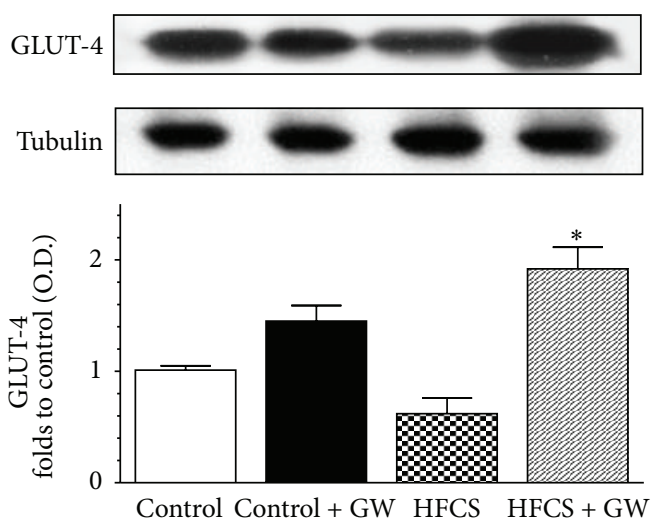

(a)

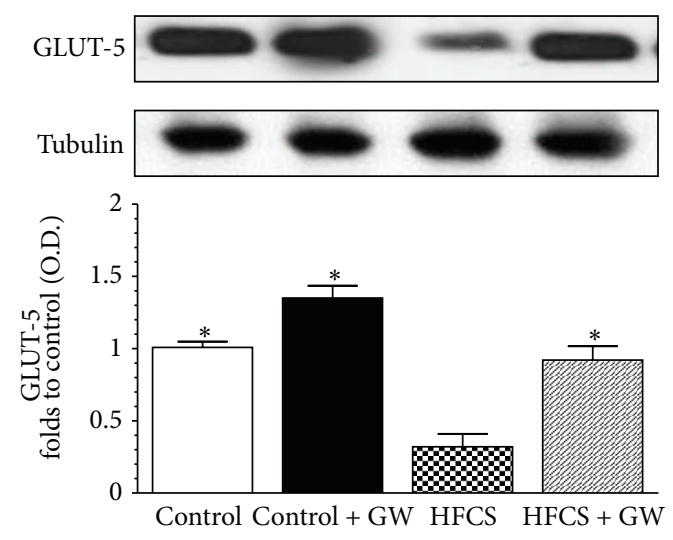

(c)
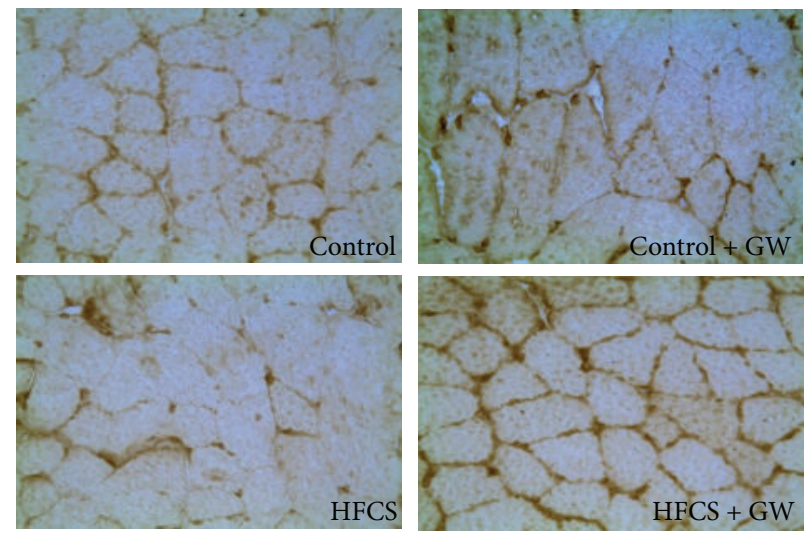

(b)

GLUT-5
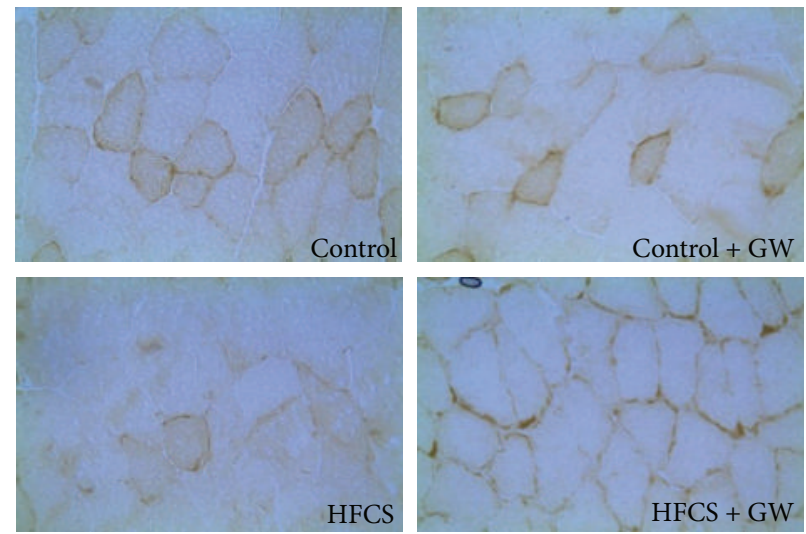

(d)

FIGURE 3: Effects of two dietary regimens either normal (control) or a diet enriched with 15\% HFCS solution (HFCS) on GLUT-4 and GLUT-5 expression (resp., (a) and (c)) and membrane translocation (resp., (b) and (d), original magnification: 400x) in the gastrocnemius of mice treated with GW0742 $(1 \mathrm{mg} / \mathrm{kg} /$ day, control + GW; HFCS + GW). Densitometric analysis of the bands is expressed as relative optical density (O.D.), corrected for the corresponding tubulin, and normalized using the related control band. Data are means \pm SD of three separate experiments. ${ }^{*} P<0.01$ versus HFCS.

its substrate $\operatorname{Ser}^{79}$ ACC. Interestingly, GW0742 treatment led to a robust increase in phosphorylation of both AMPK and ACC in HFCS-fed mice (Figures 5(a) and 5(b)). The effects of PPAR- $\delta$ agonism on fatty acid oxidation in skeletal muscle cells are further indicated by the significant increase in the protein expression of carnitine palmitoyl transferase-1 (CPT1) elicited by GW0742 in HFCS-fed mice (Figure 5(c)).

\subsection{Effects of HFCS Diet and GW0742 Treatment on NF- $\kappa B$} Activation, ICAM-1, and iNOS Expression. To investigate the muscle inflammatory response induced by HFCS-diet and the intracellular signaling pathway(s) that might be involved in the protective mechanisms evoked by GW0742, we firstly evaluated the effects on NF- $\kappa \mathrm{B}$ activation. When compared to control mice, HFCS mice developed significant increase in the nuclear translocation of the p $65 \mathrm{NF}-\kappa \mathrm{B}$ subunit in the mouse gastrocnemius, indicating the activation of this transcriptional factor (Figure 6(a)). Treatment with GW0742 resulted in a significant reduction in nuclear translocation of p 65 and, hence, in the activation of NF- $\kappa$ B. The intercellular adhesion molecule-1 (ICAM-1), whose role in the recruitment of neutrophils is widely accepted, was slightly detected in the gastrocnemius of control animals, whereas its expression was dramatically increased by HFCS diet (Figure 6(b)). As shown in Figure 6(c), also the expression of the inducible nitric oxide synthase (iNOS) was increased in the presence of dietary manipulation. Interestingly, these changes were suppressed by GW0742 administration, as evidenced by densitometric analysis of the related autoradiograms.

\subsection{Effects of HFCS Diet and GW0742 Treatment on Skeletal} Muscle FGF-21 Production. The beneficial effects of PPAR- $\delta$ activation were associated with a dramatic increase of FGF21 production in the mouse gastrocnemius. As shown in Figure 7 , in comparison to control mice $(46.45 \pm 1.13 \mathrm{pg} / \mathrm{mg}$ protein), HFCS diet did not affect the production of this 


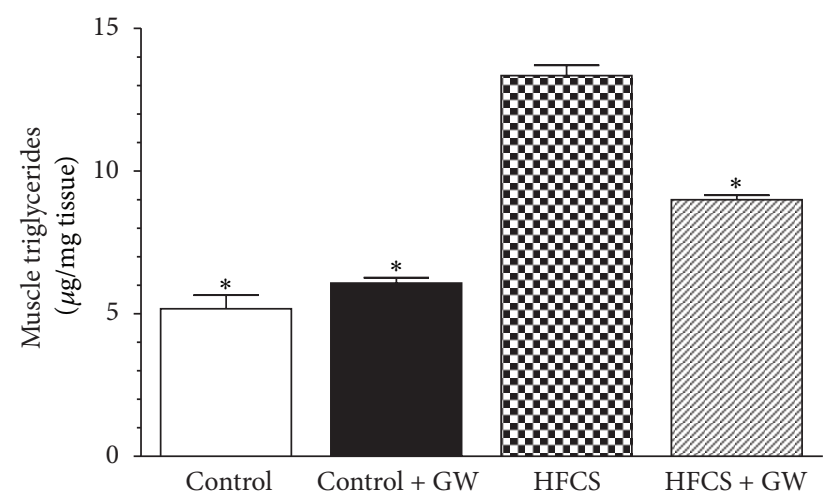

Figure 4: Triglyceride content in gastrocnemius of mice fed with a standard diet (control) or a HFCS diet (HFCS) for 30 weeks and treated with GW0742 (1 mg/kg/day) added during the last 16 weeks (control + GW; HFCS + GW). Data are means \pm SD of eight animals/group. ${ }^{*} P<0.01$ versus HFCS.

myokine (49.38 $\pm 4.12 \mathrm{pg} / \mathrm{mg}$ protein), whereas GW0742 treatment induced a twofold increase $(87.08 \pm 6.37 \mathrm{pg} / \mathrm{mg}$ protein).

\section{Discussion}

In agreement with previous observations $[14,15]$, the present study shows that chronic exposure to the most widely used added sugar HFCS caused a significant increase in body mass associated with increases in serum levels of triglycerides, LDL-cholesterol, glucose, insulin, IL-6, leptin, and hypoadiponectinemia. Using the same experimental protocol here reported, we have recently demonstrated that the molecular mechanism underlying the deleterious effects of HFCS involves the hepatic upregulation of fructokinase, the main fructose-metabolizing enzyme, which may account for the increase in serum levels of free fatty acids and hyperuricemia [5]. We also reported that the documented increase in serum uric acid level significantly contributed to the development of chronic kidney injury. Interestingly, we demonstrated that chronic administration of the PPAR- $\delta$ ligand GW0742 exerted beneficial effects by preventing the upregulation of fructokinase in the liver and activation of the inflammatory signaling complex NLRP3 inflammasome in the kidney. Despite these preliminary data, so far, there are no studies on the effects of long-term exposure to HFCS, the major sweetener added to beverages and food, on skeletal muscle, which is a major site of postprandial glucose disposal and is therefore one of the insulin-sensitive tissues most likely to manifest early signs of insulin resistance. Here, we investigated (i) the mechanisms underlying metabolic disturbances in skeletal muscle of mice exposed for 30 weeks to high intake of HFCS and (ii) the local effects evoked by PPAR- $\delta$ chronic activation. The sugar was added to the drink water at a concentration that covers $10 \%$ of the daily caloric intake, corresponding to the average energy intake in the form of ingested sweeteners in the western diet. We documented the HFCS-induced alteration in the insulin signal transduction pathway, as shown by the impaired phosphorylation of IRS1 protein as well as of the downstream key insulin signaling molecules, Akt, and GSK-3 $\beta$, an Akt substrate [16]. This is in keeping with previous studies showing that IRS-1 serine phosphorylation can interfere with subsequent Akt and GSK$3 \beta$ phosphorylation, disrupting insulin signal transduction [17]. In our experimental model, oral administration of the selective PPAR- $\delta$ agonist GW0742 was associated with a significant improvement of the defective insulin signaling in the skeletal muscle, which may account at least in part for the changes in serum lipid profile and insulin sensitivity. As the inhibition of GSK-3 $\beta$ evokes an increase in the glycogen synthesis $[18,19]$, we may speculate that GW0742 administration modulates muscle glycogen storage through inactivation of GSK-3 $\beta$. Although no direct evidence of drug treatment on glucose storage has been reported in our study, we documented the effects of chronic PPAR$\delta$ activation on glucose transporters expression and distribution. Specifically, we found that PPAR- $\delta$ activation by GW0742 evoked an increase in expression of GLUT-4, the most abundant glucose transporter isoform in skeletal muscle [20], and its translocation from intracellular compartments to the plasma membrane, thus facilitating glucose transport. Similarly, GLUT-5, the fructose carrier with low capacity to transport glucose [21], was scarcely detectable in the gastrocnemius muscle of HFCS-fed mice, and its expression and membrane translocation were enhanced by chronic PPAR$\delta$ activation. Because fructose is highly present in the HFCS diet and contributes to carbohydrate metabolism in muscle [22], the increase in GLUT-5 may favor a better utilization of fructose supplied in the diet. In any case, the reduction in GLUT-4 and GLUT-5 expression and translocation detected in the HFCS group could represent an adaptation to the chronic exposure to a sugar-enriched diet, while the increases in these carrier isoforms in the presence of the selective PPAR- $\delta$ agonist GW0742 may account, at least in part, for the improvement in insulin-induced muscle glucose uptake. Recent data have shown that Akt inhibitors or dominantnegative Akt constructs regulate the translocation, targeting, and fusion of GLUT-4-containing vesicles [23, 24]. Similarly, IRS-1 phosphorylation has been reported to affect GLUT-4 translocation and subsequent glucose uptake in mouse skeletal myocytes [25]. We may, thus, speculate that the beneficial effects of the PPAR- $\delta$ ligand GW0742 are secondary to activation of the IRS-1/Akt/GSK-3 $\beta$ pathway. This is also supported by previous findings showing that the chronic administration of GW0742 in rats results in phosphoinositide-dependent kinase phosphorylation and, hence, increased Akt phosphorylation [26]. Another enzyme complex which could be involved in PPAR- $\delta$ metabolic effects within the skeletal muscle is AMPK, a serine/threonine protein kinase that has emerged as a key player in both lipid and glucose metabolism in skeletal muscles [27, 28]. In mouse $\mathrm{C} 2 \mathrm{C} 12$ myotubes, AMPK activation potentiated insulin action by reducing IRS-1 serine phosphorylation [29], while reduced muscle AMPK activity has been reported to aggravate muscle insulin resistance following a high-fat diet over 30 weeks [30]. In agreement with these observations, we found that GW0742 increased phosphorylation 

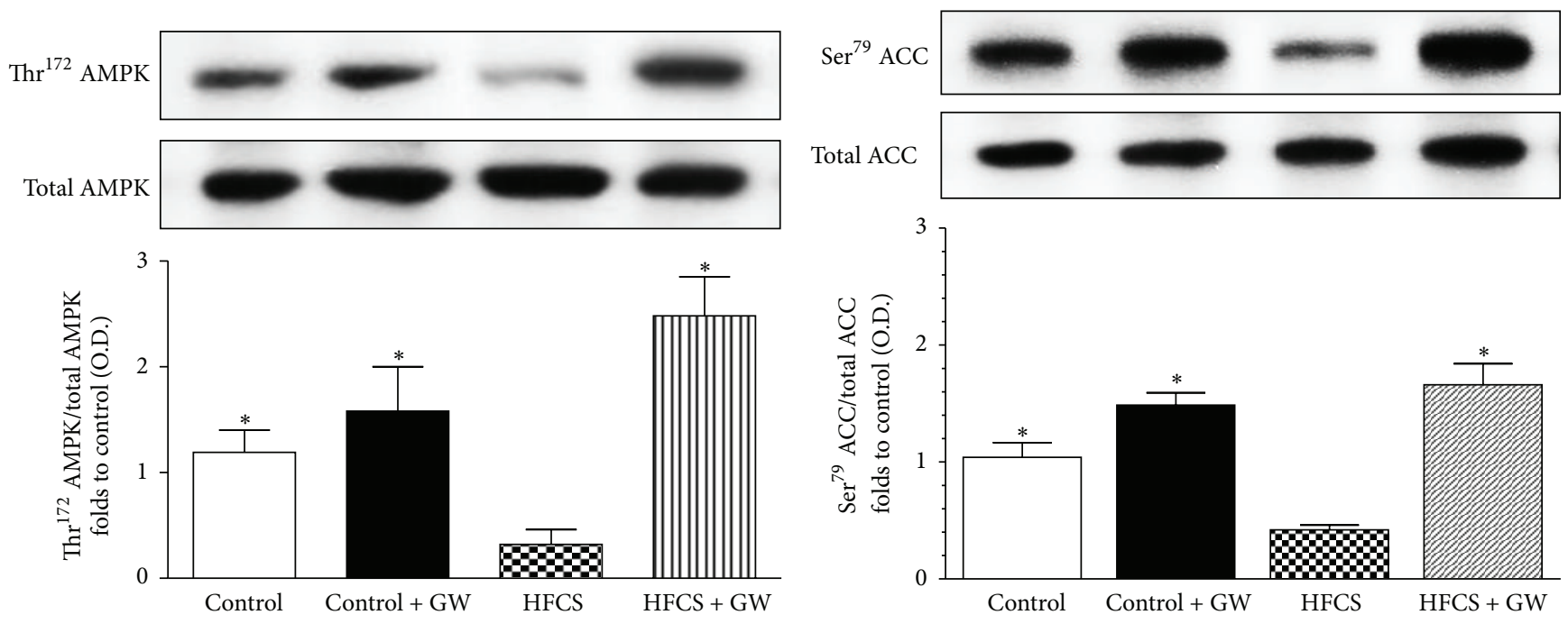

(a)

(b)
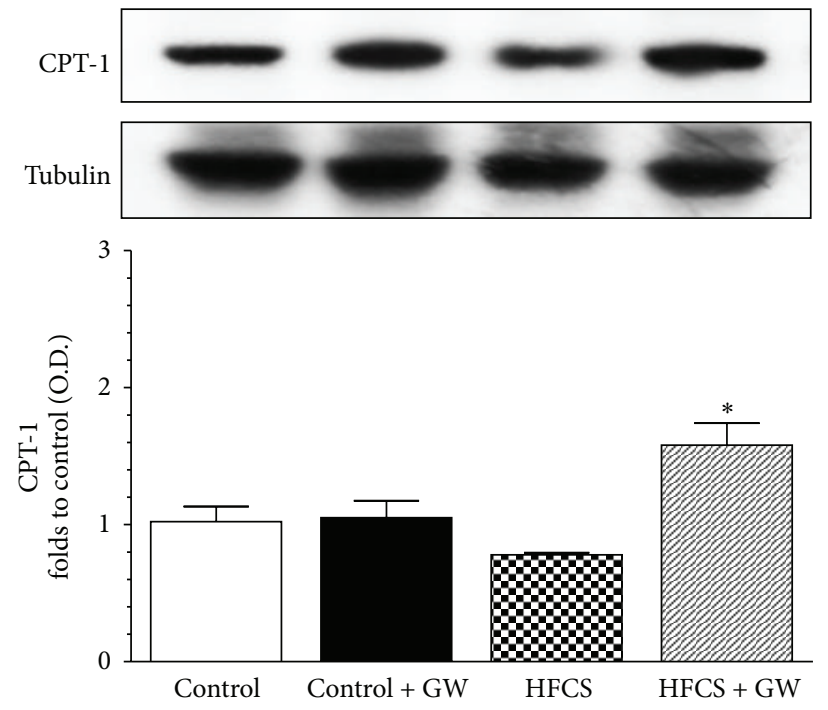

(c)

FIGURE 5: Effects of GW0742 treatment on AMPK/ACC phosphorylation and CPT-1 expression in the gastrocnemius of mice fed with HFCS diet. Total AMPK protein expression and $\mathrm{Thr}^{172}$ phosphorylation (a), total ACC protein expression and Ser ${ }^{79}$ phosphorylation (b), and CPT-1 expression (c) were analyzed by western blot on the gastrocnemius homogenates obtained from mice fed with a standard (control) or HFCS diet (HFCS) for 30 weeks and treated with GW0742 (1 mg/kg/day) added during the last 16 weeks (control + GW; HFCS + GW). Densitometric analysis of the bands is expressed as relative optical density (O.D.), corrected for the corresponding tubulin contents, and normalized using the related control band. The data are means \pm SD of three separate experiments. ${ }^{*} P<0.01$ versus HFCS.

of $\mathrm{Thr}^{172}$ regulatory site on AMPK which, in turn, causes ACC phosphorylation. When ACC is inactive (phosphorylated form), a fall in malonyl-coenzyme A occurs, which disinhibits CPT-1 and increases mitochondrial import and oxidation of long-chain fatty acids [31]. Our data demonstrate that chronic exposure to GW0742 administration increased skeletal muscle CPT-1 expression, thus shunting toward fatty acid oxidation, and this effect was associated with reduced triglyceride accumulation. These findings suggest that the beneficial effects evoked by the PPAR- $\delta$ agonist GW0742 are at least partially dependent on AMPK activation. The direct involvement of PPAR- $\delta$ agonism in mediating improvements in muscle insulin sensitivity and lipid metabolism is also confirmed by results showing that PPAR- $\delta$ is expressed in the gastrocnemius of both control and HFCS-fed mice and, more importantly, that its expression is substantially increased by chronic administration of GW0742, thus suggesting that the observed drug effects are due to a ligand-dependent PPAR$\delta$ activation. This is consistent with previous works showing that PPAR- $\delta$ activation is involved in regulating myogenesis [32-35]. In search of the mechanism(s) underlying the protective action of GW0742, we investigated whether PPAR- $\delta$ activation may affect the local inflammatory response associated with muscular metabolic injury. Although PPAR- $\delta$ has 

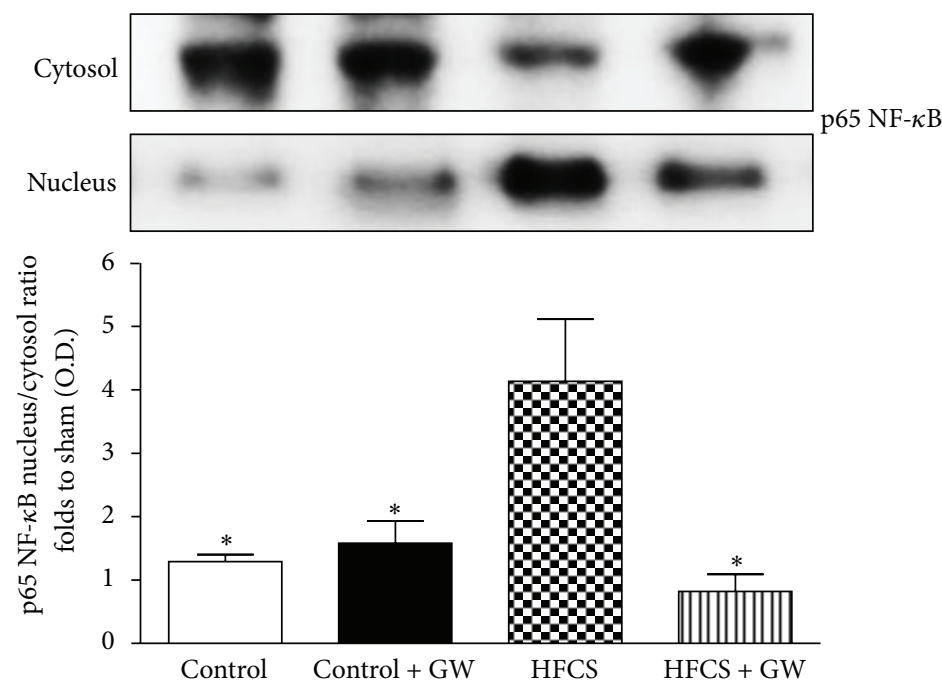

(a)
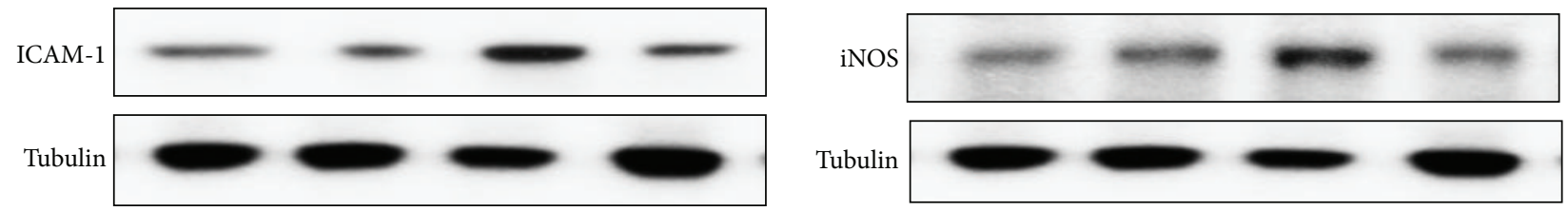

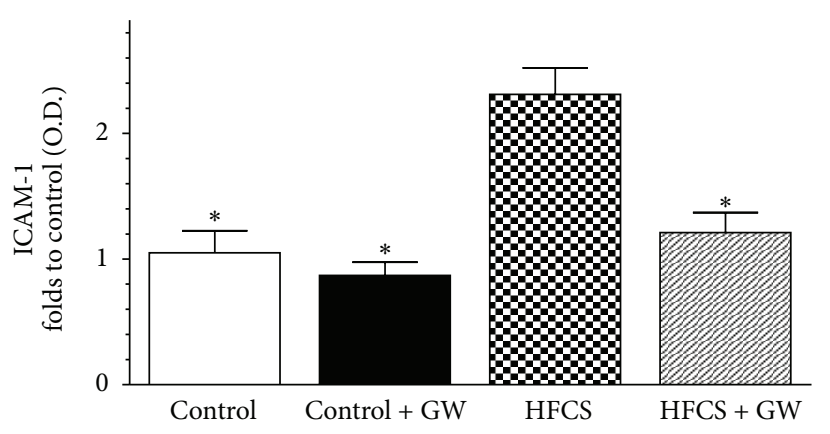

(b)

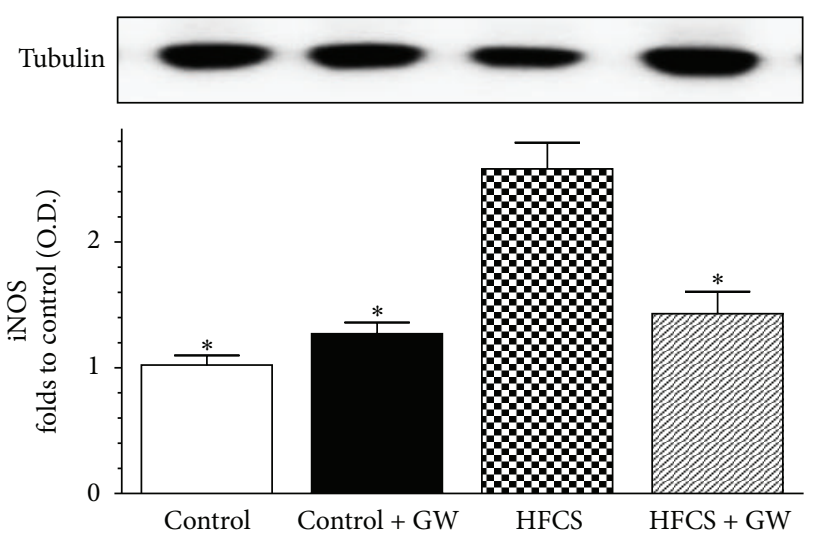

(c)

FIGURE 6: Effects of dietary manipulation and GW0742 treatment on NF- $\kappa$ B p65 translocation (a), ICAM-1 (b) and iNOS (c) protein expression in the mouse gastrocnemius. Protein expression was measured by Western blot analysis in gastrocnemius homogenates of mice fed with a standard (control) or HFCS diet (HFCS) in the absence or presence of GW0742 treatment (1 mg/kg/day) (control+ GW; HFCS + GW). Densitometric analysis of the bands is expressed as relative optical density (O.D.), corrected for the corresponding tubulin contents, and normalized using the related control band. NF- $\kappa \mathrm{B}$ p65 subunit levels in cytosolic and nuclear fractions are expressed as nucleus/cytosol ratio normalized using the related control band. Data are means $\pm \mathrm{SD}$ of three separate experiments. ${ }^{*} P<0.01$ versus HFCS.

been implicated in the regulation of systemic inflammatory responses associated with metabolic dysregulation [7], so far, reports on anti-inflammatory effects of PPAR activation in skeletal muscle are rather scarce. Here, we show for the first time that in the skeletal muscle GW0742 reverts the diet-induced increase in the nuclear translocation of $\mathrm{NF}-\kappa \mathrm{B}$ p65, a transcriptional factor that plays an important role in regulating the transcription of a number of genes, especially those involved in producing mediators of local and systemic inflammation (such as cytokines, chemokines, and cell adhesion molecules). This observation is in agreement with previous studies reporting that PPAR- $\delta$ activation induces the physical interaction between PPAR- $\delta$ and the p65 subunit of NF- $\kappa \mathrm{B}$ and reduced the LPS-induced degradation of the inhibitory protein "Inhibitor of kappa B," thus preventing NF$\kappa \mathrm{B}$ activation $[36,37]$. The reduction of NF- $\kappa \mathrm{B}$ activation by GW0742 treatment may account for the observed reduction in the serum levels of IL-6, which is known to be mostly released from skeletal muscle, and in the local expression of the NF- $\kappa$ B-dependent proteins iNOS and ICAM-1, whose role in the development of insulin resistance has been recently documented [38, 39]. As several studies have reported an association between GSK- $3 \beta$ and NF- $\kappa$ B activity [40], we might speculate that PPAR- $\delta$ activation phosphorylates, and hence, activates the Akt pathway, which in turn phosphorylates, and hence, inhibits GSK-3 $\beta$, presumably resulting 


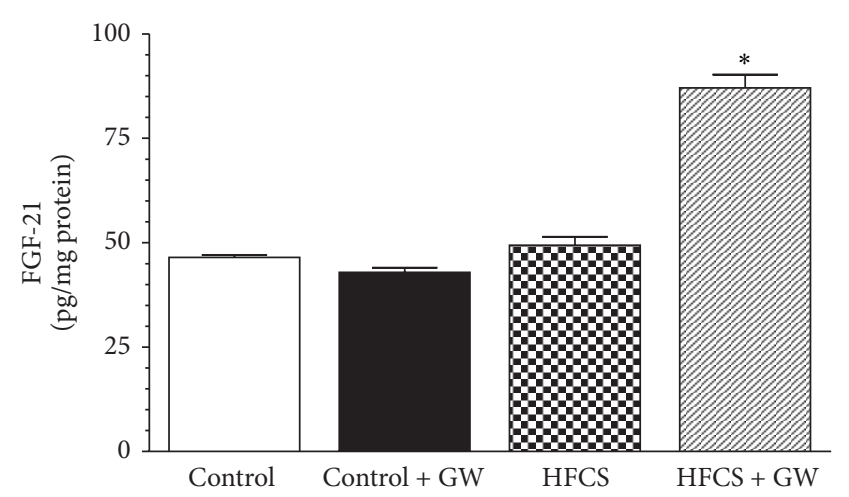

FigURE 7: Fibroblast growth factor-21 (FGF-21) levels were analyzed by ELISA in gastrocnemius homogenates of mice fed with a standard (control) or HFCS diet in the absence or presence of GW0742 $(1 \mathrm{mg} / \mathrm{kg} /$ day $)$. Data are means $\pm \mathrm{SD}$ of five animals/group. ${ }^{*} P<0.01$ versus HFCS.

in the inhibition of NF- $\kappa \mathrm{B}$ and, in turn, NF- $\kappa \mathrm{B}$-dependent proinflammatory gene transcription. Although this cross talk among different signaling pathways by pharmacological PPAR- $\delta$ modulation is intriguing, it must be stressed, however, that the lack of direct experimental evidence of a causal relationship between the improved local and systemic insulin sensitivity and the treatment-induced reduction of NF- $\kappa \mathrm{B}$ activation in our experimental model limit the interpretation of the molecular mechanism(s) underlying our findings. One of the most recently identified mediators that facilitates organ cross talk and the related control of impaired glucose homeostasis in metabolic diseases is a member of the FGF family, FGF-21. FGF-21 has been previously shown to lower blood glucose levels in several diabetic rodent and monkey models [41, 42], to regulate lypolisis in white adipose tissue $[43,44]$ and substrate utilization in the liver [45]. FGF-21 was also shown to directly enhance skeletal muscle glucose uptake [46]. The metabolic effects of FGF-21 on glucose metabolism involve selective regulation by different PPAR isoforms. Liver-derived FGF-21 is stimulated by PPAR- $\alpha$ ligands [47]. Conversely, PPAR- $\gamma$ activation with feeding promotes FGF21 production in adipocytes but not in liver $[48,49]$. To our knowledge, this is the first paper that demonstrates a correlation between PPAR- $\delta$ activation and increased FGF21 levels in skeletal muscle, thus adding an original piece of evidence to the complex mechanisms by which PPAR- $\delta$ can regulate several biological functions. Our observation is also in keeping with a previous study showing that circulating FGF-21 levels consistently increase in human subjects in response to pharmacological activation of PPAR- $\delta$ [50]. Although a previous investigation has revealed that PPAR- $\gamma$ directly regulates expression of the FGF-21 gene through elements located within the 500-bp upstream region of the gene [49], to date, a consensus sequence of PPAR- $\delta$ binding site in the promoter region of the FGF-21 gene has not yet been identified. Besides in vitro experiments with FGF-21, small interfering RNA are warranted to clarify whether GW0742 beneficial effects are related to the direct modulation of
FGF-21 biological functions. The recent findings on FGF21 ability to prevent insulin resistance in human myoblasts by inhibiting NF- $\kappa \mathrm{B}$ activation [51] may also suggest that the muscle-derived FGF-21 acts in an autocrine fashion to amplify PPAR- $\delta$ inhibitory effects on the expression of NF$\kappa \mathrm{B}$-dependent inflammatory genes. This further supports the existence of multiple anti-inflammatory pathways involved in the beneficial effects evoked by PPAR- $\delta$ activation.

In conclusion, we have shown that feeding mice with a HFCS diet for 30 weeks evoked skeletal muscle insulin resistance and lipid accumulation which were associated with activation of inflammatory pathways. All these effects were attenuated by selective PPAR- $\delta$ activation. In addition, this study, showing a strong induction of FGF-21 in the skeletal muscle after chronic administration of the PPAR- $\delta$ ligand GW0742, enhances our knowledge of the mechanisms of action of PPAR- $\delta$ agonism and provides further insights into the role of FGF-21 as mediator of the tissue crosstalk that underlines the integrated control of the metabolic inflammation.

\section{Authors' Contribution}

Elisa Benetti and Raffaella Mastrocola contributed equally to this work. Massimo Collino and Marco A. Minetto are shared senior authors of this study.

\section{Acknowledgments}

This study was supported by the bank foundations "Compagnia di San Paolo" of Turin, Italy (Project "Neuromuscular Investigation and Conditioning in Endocrine Myopathies") and "Fondazione CARIPLO" of Milan, Italy (Project "Steroid myopathy: Molecular, Histopathological, and Electrophysiological Characterization").

\section{References}

[1] V. T. Samuel and G. I. Shulman, "Mechanisms for insulin resistance: common threads and missing links," Cell, vol. 148, no. 5, pp. 852-871, 2012.

[2] J. Hoeks, J. de Wilde, M. F. M. Hulshof et al., "High fat dietinduced changes in mouse muscle mitochondrial phospholipids do not impair mitochondrial respiration despite insulin resistance," PLoS ONE, vol. 6, no. 11, Article ID e27274, 2011.

[3] A. Vijayakumar, Y. Wu, H. Sun et al., "Targeted loss of ghr signaling in mouse skeletal muscle protects against high-fat diet-induced metabolic deterioration," Diabetes, vol. 61, no. 1, pp. 94-103, 2012.

[4] P. M. Badin, I. K. Vila, K. Louche et al., "High-fat diet-mediated lipotoxicity and insulin resistance is related to impaired lipase expression in mouse skeletal muscle," Endocrinology, vol. 154, no. 4, pp. 1444-1453, 2013.

[5] M. Collino, E. Benetti, M. Rogazzo et al., "Reversal of the deleterious effects of chronic dietary HFCS-55 intake by PPAR$\delta$ agonism correlates with impaired NLRP3 inflammasome activation," Biochemical Pharmacology, vol. 85, no. 2, pp. 257264, 2013.

[6] M. Collino, "High dietary fructose intake: sweet or bitter life?" World Journal of Diabetes, vol. 2, pp. 77-81, 2011. 
[7] E. Benetti, N. S. A. Patel, and M. Collino, "The role of $\operatorname{PPAR} \beta / \delta$ in the management of metabolic syndrome and its associated cardiovascular complications," Endocrine, Metabolic and Immune Disorders - Drug Targets, vol. 11, no. 4, pp. 273-284, 2011.

[8] G. D. Barish, V. A. Narkar, and R. M. Evans, "PPAR $\delta$ : a dagger in the heart of the metabolic syndrome," Journal of Clinical Investigation, vol. 116, no. 3, pp. 590-597, 2006.

[9] M. Schuler, F. Ali, C. Chambon et al., "PGCl $\alpha$ expression is controlled in skeletal muscles by $\operatorname{PPAR} \beta$, whose ablation results in fiber-type switching, obesity, and type 2 diabetes," Cell Metabolism, vol. 4, no. 5, pp. 407-414, 2006.

[10] L. Li, Z. Luo, H. Yu et al., "Telmisartan improves insulin resistance of skeletal muscle through peroxisome proliferatoractivated receptor- $\delta$ activation," Diabetes, vol. 62 , no. 3 , pp. $762-$ 774,2013

[11] D. Cuevas-Ramos, C. A. Aguilar-Salinas, and F. J. GomezPerez, "Metabolic actions of fibroblast growth factor 21," Current Opinion in Pediatrics, vol. 24, no. 4, pp. 523-529, 2012.

[12] T. L. Graham, C. Mookherjee, K. E. Suckling, C. N. A. Palmer, and L. Patel, "The PPAR $\delta$ agonist GW0742X reduces atherosclerosis in $\mathrm{LDLR}^{-/-}$mice," Atherosclerosis, vol. 181, no. 1, pp. 29-37, 2005.

[13] D. R. Meldrum, R. Shenkar, B. C. Sheridan, B. S. Cain, E. Abraham, and A. H. Harken, "Hemorrhage activates myocardial $\mathrm{NF} \kappa \mathrm{B}$ and increases TNF- $\alpha$ in the heart," Journal of Molecular and Cellular Cardiology, vol. 29, no. 10, pp. 2849-2854, 1997.

[14] K. S. Collison, S. M. Saleh, R. H. Bakheet et al., "Diabetes of the liver: the link between nonalcoholic fatty liver disease and HFCS-55," Obesity, vol. 17, no. 11, pp. 2003-2013, 2009.

[15] H. R. Light, E. Tsanzi, J. Gigliotti, K. Morgan, and J. C. Tou, “The type of caloric sweetener added to water influences weight gain, fat mass, and reproduction in growing Sprague-Dawley female rats," Experimental Biology and Medicine, vol. 234, no. 6, pp. 651661, 2009.

[16] P. Cohen and M. Goedert, "GSK3 inhibitors: development and therapeutic potential," Nature Reviews Drug Discovery, vol. 3, no. 6, pp. 479-487, 2004.

[17] C. M. Taniguchi, B. Emanuelli, and C. R. Kahn, "Critical nodes in signalling pathways: insights into insulin action," Nature Reviews Molecular Cell Biology, vol. 7, no. 2, pp. 85-96, 2006.

[18] D. A. E. Cross, D. R. Alessi, P. Cohen, M. Andjelkovich, and B. A. Hemmings, "Inhibition of glycogen synthase kinase- 3 by insulin mediated by protein kinase B," Nature, vol. 378, no. 6559, pp. 785-789, 1995.

[19] J. N. Nielsen and J. F. P. Wojtaszewski, "Regulation of glycogen synthase activity and phosphorylation by exercise," Proceedings of the Nutrition Society, vol. 63, no. 2, pp. 233-237, 2004.

[20] K. Bouzakri, A. Zachrisson, L. Al-Khalili et al., "siRNA-based gene silencing reveals specialized roles of IRS-1/Akt2 and IRS2/Aktl in glucose and lipid metabolism in human skeletal muscle," Cell Metabolism, vol. 4, no. 1, pp. 89-96, 2006.

[21] G. W. Gould and G. D. Holman, "The glucose transporter family: structure, function and tissue-specific expression," Biochemical Journal, vol. 295, part 2, pp. 329-341, 1993.

[22] J. R. Zierath, L. A. Nolte, E. Wahlstrom et al., "Carriermediated fructose uptake significantly contributes to carbohydrate metabolism in human skeletal muscle," Biochemical Journal, vol. 311, part 2, pp. 517-521, 1995.

[23] E. Gonzalez and T. E. McGraw, "Insulin signaling diverges into Akt-dependent and -independent signals to regulate the recruitment/docking and the fusion of GLUT4 vesicles to the plasma membrane," Molecular Biology of the Cell, vol. 17, no. 10, pp. 4484-4493, 2006.

[24] D. Leto and A. R. Saltiel, "Regulation of glucose transport by insulin: traffic control of GLUT4," Nature Reviews Molecular Cell Biology, vol. 13, no. 6, pp. 383-396, 2012.

[25] X. Zeng, C. Zhang, M. Tong et al., "Knockdown of NYGGF4 increases glucose transport in $\mathrm{C} 2 \mathrm{C} 12$ mice skeletal myocytes by activation IRS-1/PI3K/AKT insulin pathway," Journal of Bioenergetics and Biomembranes, vol. 44, no. 3, pp. 351-355, 2012.

[26] T. Yue, S. S. Nerurkar, W. Bao et al., "In vivo activation of peroxisome proliferator-activated receptor- $\delta$ protects the heart from ischemia/reperfusion injury in Zucker fatty rats," Journal of Pharmacology and Experimental Therapeutics, vol. 325, no. 2, pp. 466-474, 2008.

[27] B. F. Holmes, E. J. Kurth-Kraczek, and W. W. Winder, "Chronic activation of $5^{\prime}$-AMP-activated protein kinase increases GLUT4, hexokinase, and glycogen in muscle," Journal of Applied Physiology, vol. 87, no. 5, pp. 1990-1995, 1999.

[28] N. Musi and L. J. Goodyear, "AMP-activated protein kinase and muscle glucose uptake," Acta Physiologica Scandinavica, vol. 178, no. 4, pp. 337-345, 2003.

[29] S. N. Jakobsen, D. G. Hardie, N. Morrice, and H. E. Tornqvist, "5/-AMP-activated protein kinase phosphorylates IRS1 on Ser-789 in mouse C2C12 myotubes in response to 5aminoimidazole-4-carboxamide riboside," The Journal of Biological Chemistry, vol. 276, no. 50, pp. 46912-46916, 2001.

[30] N. Fujii, R. C. Ho, Y. Manabe et al., "Ablation of AMPactivated protein kinase $\alpha 2$ activity exacerbates insulin resistance induced by high-fat feeding of mice," Diabetes, vol. 57, no. 11, pp. 2958-2966, 2008.

[31] N. B. Ruderman, A. K. Saha, and E. W. Kraegen, "Minireview: malonyl CoA, AMP-activated protein kinase, and adiposity," Endocrinology, vol. 144, no. 12, pp. 5166-5171, 2003.

[32] S. Luquet, J. Lopez-Soriano, D. Holst et al., "Peroxisome proliferator-activated receptor $\delta$ controls muscle development and oxidative capability," FASEB Journal, vol. 17, no. 15, pp. 2299-2301, 2003.

[33] T. Tanaka, J. Yamamoto, S. Iwasaki et al., "Activation of peroxisome proliferator-activated receptor $\delta$ induces fatty acid $\beta$-oxidation in skeletal muscle and attenuates metabolic syndrome," Proceedings of the National Academy of Sciences of the United States of America, vol. 100, no. 26, pp. 15924-15929, 2003.

[34] Y. Wang, C. Zhang, R. T. Yu et al., "Regulation of muscle fiber type and running endurance by PPAR $\delta$," PLoS Biology, vol. 2, no. 10, article e294, 2004.

[35] S. Bonala, S. Lokireddy, H. Arigela et al., "Peroxisome proliferator-activated receptor $\beta / \delta$ induces myogenesis by modulating myostatin activity," The Journal of Biological Chemistry, vol. 287, no. 16, pp. 12935-12951, 2012.

[36] A. Planavila, R. Rodríguez-Calvo, M. Jové et al., "Peroxisome proliferator-activated receptor $\beta / \delta$ activation inhibits hypertrophy in neonatal rat cardiomyocytes," Cardiovascular Research, vol. 65, no. 4, pp. 832-841, 2005.

[37] G. Ding, L. Cheng, Q. Qin, S. Frontin, and Q. Yang, "PPAR $\delta$ modulates lipopolysaccharide-induced TNF $\alpha$ inflammation signaling in cultured cardiomyocytes," Journal of Molecular and Cellular Cardiology, vol. 40, no. 6, pp. 821-828, 2006.

[38] A. F. Rubio-Guerra, H. Vargas-Robles, A. M. Serrano, G. Vargas-Ayala, L. Rodriguez-Lopez, and B. A. EscalanteAcosta, "Correlation between the levels of circulating adhesion 
molecules and atherosclerosis in hypertensive type-2 diabetic patients," Clinical and Experimental Hypertension, vol. 32, no. 5, pp. 308-310, 2010.

[39] E. R. Ropelle, J. R. Pauli, D. E. Cintra et al., "Targeted disruption of inducible nitric oxide synthase protects against aging, Snitrosation, and insulin resistance in muscle of male mice," Diabetes, vol. 62, no. 2, pp. 466-470, 2013.

[40] K. P. Hoeflich, J. Luo, E. A. Rubie, M. Tsao, O. Jin, and J. R. Woodgett, "Requirement for glycogen synthase kinase- $3 \beta$ in cell survival and NF- $\kappa$ B activation," Nature, vol. 406, no. 6791, pp. 86-90, 2000.

[41] A. Kharitonenkov, T. L. Shiyanova, A. Koester et al., "FGF-21 as a novel metabolic regulator," Journal of Clinical Investigation, vol. 115, no. 6, pp. 1627-1635, 2005.

[42] A. Kharitonenkov, V. J. Wroblewski, A. Koester et al., "The metabolic state of diabetic monkeys is regulated by fibroblast growth factor-21," Endocrinology, vol. 148, no. 2, pp. 774-781, 2007.

[43] P. Arner, A. Pettersson, P. J. Mitchell, J. D. Dunbar, A. Kharitonenkov, and M. Rydén, "FGF21 attenuates lipolysis in human adipocytes-a possible link to improved insulin sensitivity," FEBS Letters, vol. 582, no. 12, pp. 1725-1730, 2008.

[44] X. Li, H. Ge, J. Weiszmann et al., "Inhibition of lipolysis may contribute to the acute regulation of plasma FFA and glucose by FGF21 in ob/ob mice," FEBS Letters, vol. 583, no. 19, pp. 32303234, 2009.

[45] M. K. Badman, P. Pissios, A. R. Kennedy, G. Koukos, J. S. Flier, and E. Maratos-Flier, "Hepatic fibroblast growth factor 21 is regulated by $\operatorname{PPAR} \alpha$ and is a key mediator of hepatic lipid metabolism in ketotic states," Cell Metabolism, vol. 5, no. 6, pp. 426-437, 2007.

[46] F. L. Mashili, R. L. Austin, A. S. Deshmukh et al., "Direct effects of FGF21 on glucose uptake in human skeletal muscle: implications for type 2 diabetes and obesity," Diabetes/Metabolism Research and Reviews, vol. 27, no. 3, pp. 286-297, 2011.

[47] T. Inagaki, P. Dutchak, G. Zhao et al., "Endocrine regulation of the fasting response by PPAR $\alpha$-mediated induction of fibroblast growth factor 21," Cell Metabolism, vol. 5, no. 6, pp. 415-425, 2007.

[48] E. S. Muise, B. Azzolina, D. W. Kuo et al., "Adipose fibroblast growth factor 21 is up-regulated by peroxisome proliferatoractivated receptor $\gamma$ and altered metabolic states," Molecular Pharmacology, vol. 74, no. 2, pp. 403-412, 2008.

[49] H. Wang, L. Qiang, and S. R. Farmer, "Identification of a domain within peroxisome proliferator-activated receptor $\gamma$ regulating expression of a group of genes containing fibroblast growth factor 21 that are selectively repressed by SIRT1 in adipocytes," Molecular and Cellular Biology, vol. 28, no. 1, pp. 188-200, 2008.

[50] C. Christodoulides, P. Dyson, D. Sprecher, K. Tsintzas, and F. Karpe, "Circulating fibroblast growth factor 21 is induced by peroxisome proliferator-activated receptor agonists but not ketosis in man," Journal of Clinical Endocrinology and Metabolism, vol. 94, no. 9, pp. 3594-3601, 2009.

[51] M. S. Lee, S. Choi, E. S. Ha et al., "Fibroblast growth factor21 protects human skeletal muscle myotubes from palmitateinduced insulin resistance by inhibiting stress kinase and NF$\kappa \mathrm{B}$," Metabolism: Clinical and Experimental, vol. 61, no. 8, pp. 1142-1151, 2012. 


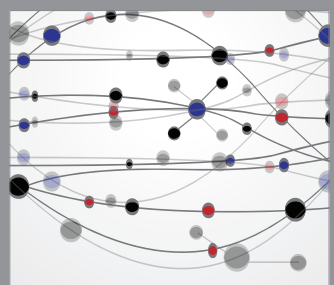

The Scientific World Journal
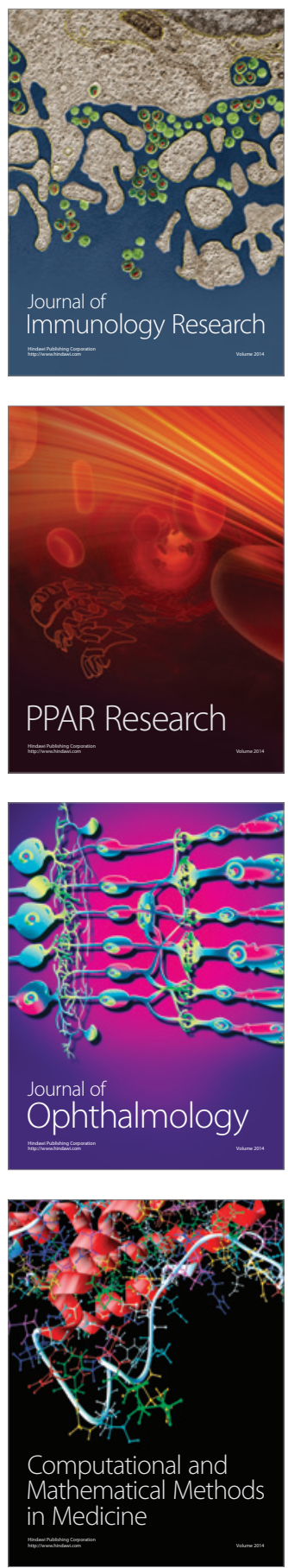

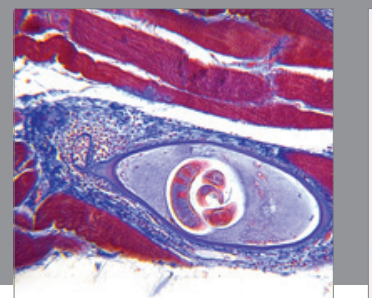

Gastroenterology

Research and Practice
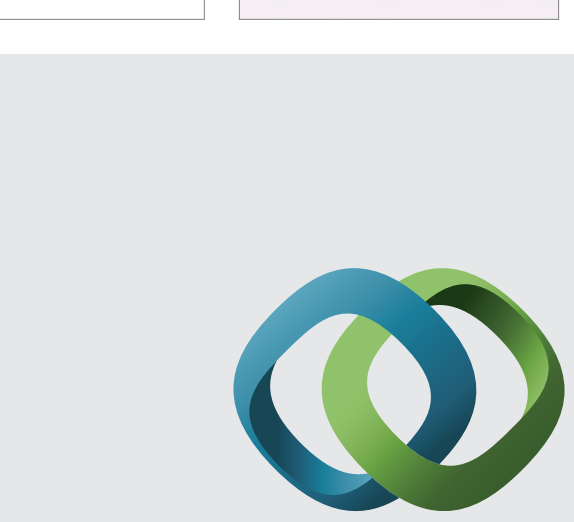

\section{Hindawi}

Submit your manuscripts at

http://www.hindawi.com
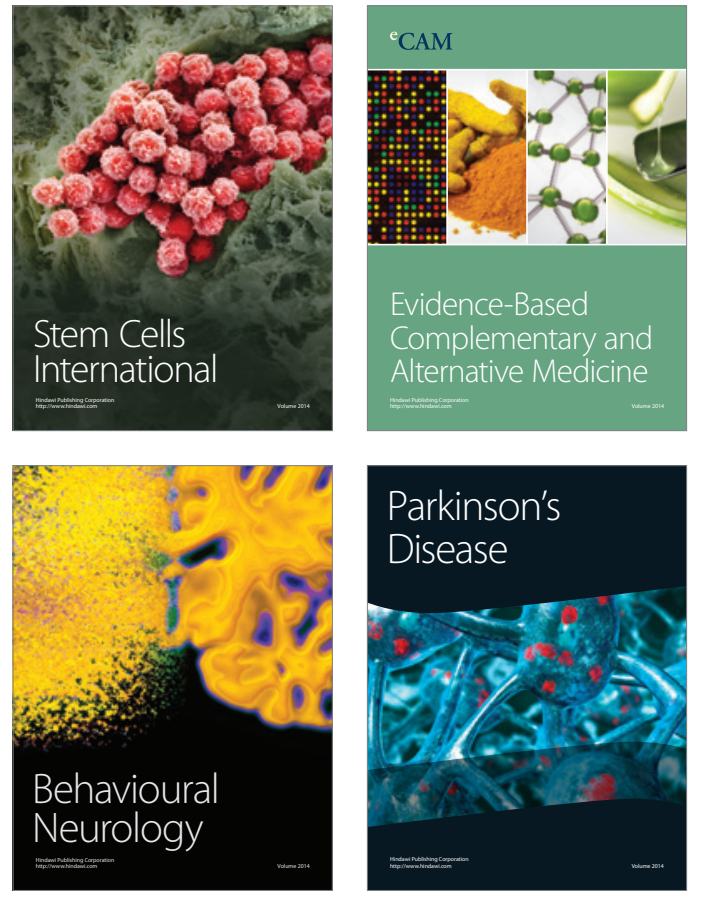
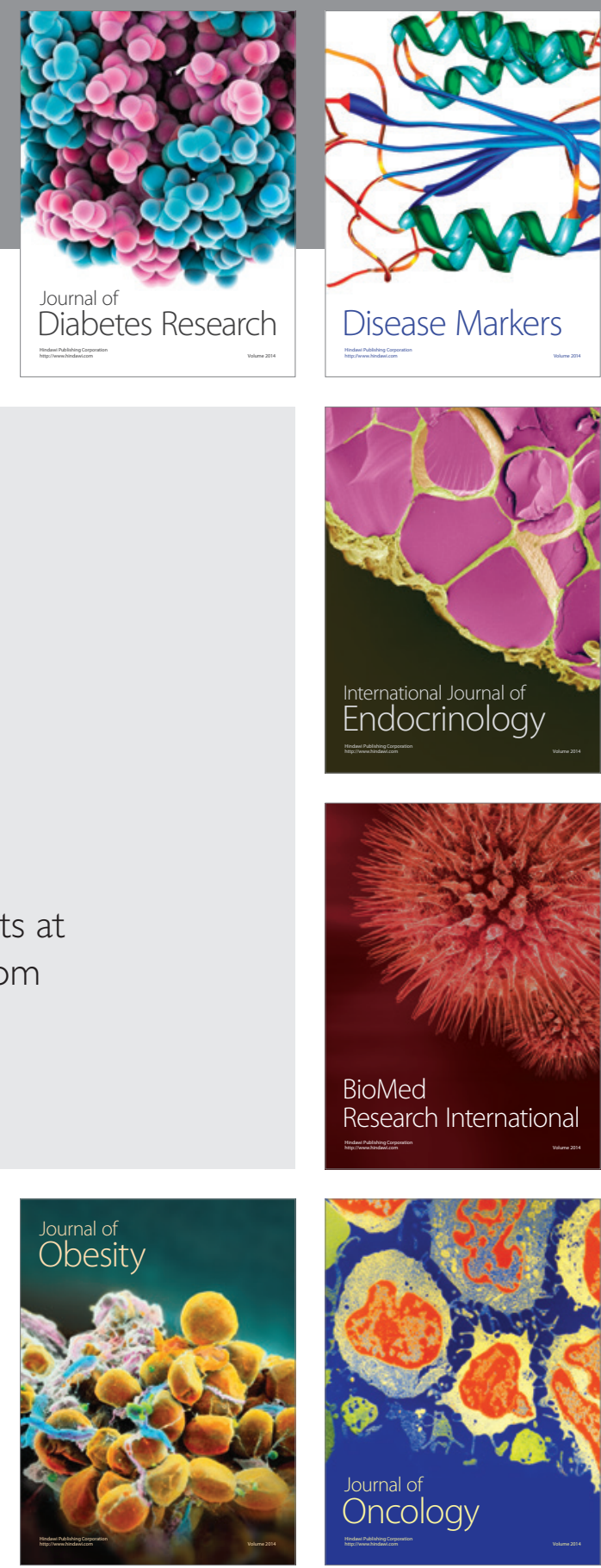

Disease Markers
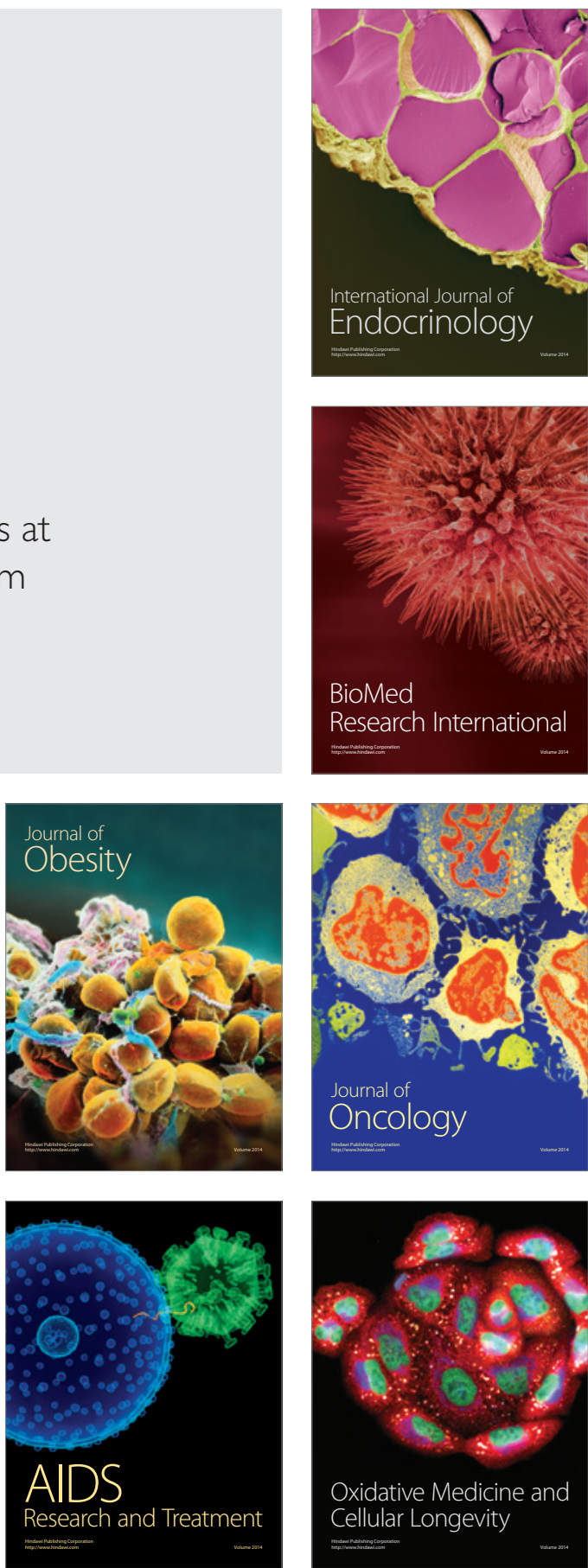